\title{
Double Lives: Transfer of fungal endophytes from leaves to woody substrates
}

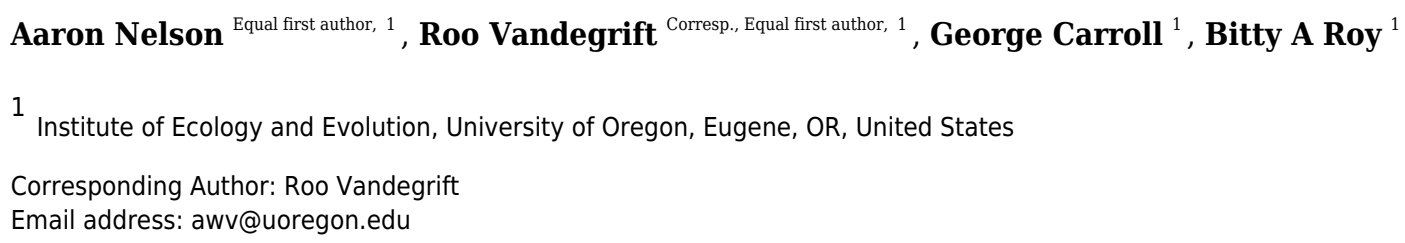

Fungal endophytes are a ubiquitous feature of plants, yet for many fungi the benefits of endophytism are still unknown. The Foraging Ascomycete (FA) hypothesis proposes that saprotrophic fungi can utilize leaves both as dispersal vehicles and as resource havens during times of scarcity. The presence of saprotrophs in leaf endophyte communities has been previously observed but their ability to transfer to non-foliar saprobic substrates has not been well investigated. To assess this ability, we conducted a culture study by placing surface-sterilized leaves from a single tropical angiosperm tree (Nectandra lineatifolia Mez) directly onto sterile wood fragments and incubating them for 6 weeks. Fungi from the wood were subsequently isolated in culture and identified to the genus level by ITS sequences or morphology. Four-hundred and seventy-seven fungal isolates comprising 24 taxa were cultured from the wood. Of these, $70.8 \%$ of taxa ( $82.3 \%$ of isolates) belong to saprotrophic genera according to the FUNGuild database. Furthermore, $27 \%$ of OTUs (6\% of isolates) were basidiomycetes, an unusually high proportion compared to typical endophyte communities. Xylaria flabelliformis, although absent in our original isolations, formed anamorphic fruiting structures on the woody substrates. We introduce the term viaphyte (literally, "by way of plant") to refer to fungi that undergo an interim stage as leaf endophytes and, after leaf senescence, colonize other woody substrates via hyphal growth. Our results support the Foraging Ascomycete hypothesis and suggest that viaphytism may play a significant role in fungal dispersal. 


\section{Double Lives: Transfer of fungal endophytes}

\section{2 from leaves to woody substrates}

3

4 Aaron Nelson $^{1 *}$, Roo Vandegrift ${ }^{1 *}$, George C. Carroll ${ }^{1}$, Bitty A. Roy ${ }^{1}$

$5{ }^{1}$ Institute of Ecology and Evolution, University of Oregon, Eugene, Oregon, USA

6

7 Corresponding author:

8 Roo Vandegrift

9 Email address: awv@uoregon.edu

$10 *$ indicates equal contribution

11

12 


\section{ABSTRACT}

14 Fungal endophytes are a ubiquitous feature of plants, yet for many fungi the benefits of

15 endophytism are still unknown. The Foraging Ascomycete (FA) hypothesis proposes that

16 saprotrophic fungi can utilize leaves both as dispersal vehicles and as resource havens during

17 times of scarcity. The presence of saprotrophs in leaf endophyte communities has been

18 previously observed but their ability to transfer to non-foliar saprobic substrates has not been

19 well investigated. To assess this ability, we conducted a culture study by placing surface-

20 sterilized leaves from a single tropical angiosperm tree (Nectandra lineatifolia Mez) directly

21 onto sterile wood fragments and incubating them for 6 weeks. Fungi from the wood were

22 subsequently isolated in culture and identified to the genus level by ITS sequences or

23 morphology. Four-hundred and seventy-seven fungal isolates comprising 24 taxa were cultured

24 from the wood. Of these, $70.8 \%$ of taxa ( $82.3 \%$ of isolates) belong to saprotrophic genera

25 according to the FUNGuild database. Furthermore, $27 \%$ of OTUs ( $6 \%$ of isolates) were

26 basidiomycetes, an unusually high proportion compared to typical endophyte communities.

27 Xylaria flabelliformis, although absent in our original isolations, formed anamorphic fruiting

28 structures on the woody substrates. We introduce the term viaphyte (literally, "by way of plant")

29 to refer to fungi that undergo an interim stage as leaf endophytes and, after leaf senescence,

30 colonize other woody substrates via hyphal growth. Our results support the Foraging

31 Ascomycete hypothesis and suggest that viaphytism may play a significant role in fungal

32 dispersal. 


\section{Introduction}

34 Endophytes are symptomless endosymbionts of living plants (Stone, Bacon \& White, 2000) and

35 are ubiquitously present in terrestrial plant tissues worldwide (Arnold \& Lutzoni, 2007).

36 Virtually every plant genus surveyed to date has documented several to hundreds of species of

37 fungal endophytes per individual, and a single plant species may host thousands of these

38 symbionts across its entire range (Martins et al., 2016; Barge et al., 2019). Although variable, the

39 effects of endophytes on host plants have attracted considerable attention (Carroll, 1988;

40 Rodriguez et al., 2009); yet, the potential benefit of endophytic life histories for the fungal

41 partners is less well explored.

The question of why fungi may adopt endophytic lifestyles has garnered a variety of

hypotheses. In particular, a number of authors have hypothesized that endophytes may be latent

44 saprotrophs that benefit from being the first to colonize plant tissues after senescence or death of

45 the host (Promputtha et al., 2007; Parfitt et al., 2010; Porras-Alfaro \& Bayman, 2011; Szink et

46 al., 2016), a phenomenon known as priority effects (Chase, 2003; Osono, 2006). Studies that

47 sampled living and decomposing leaves from the same plant individuals have observed the

48 majority of foliar endophytes can persist in the litter layer as decomposers (Osono, 2006; U'Ren

$49 \&$ Arnold, 2016), especially in the early stages of litter decomposition, when litter contains a

50 higher availability of simple sugars and other easily degradable compounds (Carroll \& Petrini,

51 1983; Voříšková \& Baldrian, 2013). Endophytes observed to persist into the late stages of litter

52 decomposition (Peršoh et al., 2013) often have demonstrated an ability to degrade more complex

53 substrates, such as lignin, which supports the hypothesis that some fungi with an endophytic life

54 stage may also play a role during later stages of litter decay (Osono \& Takeda, 1999). Although

55 the majority of studies have focused on foliar endophytes, Parfitt et al. (2010) suggest that most, 
56 if not all, trees carry sapwood endophytes with the potential to degrade the woody tissues of their

57 host when environmental and biological conditions are conducive to decay. In contrast, other

58 studies have suggested endophytes are primarily mutualists, with their fitness directly tied to that

59 of their hosts. This is exemplified best by clavicipitaceous grass endophytes, which benefit from

60 direct vertical transmission to their hosts' offspring (Clay, 1988; Hodgson et al., 2014). Finally,

61 it has been hypothesized that endophytes may be latent pathogens waiting to exploit a weakened

62 state of their host (Carroll, 1988; Slippers \& Wingfield, 2007). However, the vast majority of

63 observed endophytic fungi do not fit neatly into one of these categories and may in fact be

64 capable of a variety of context-dependent interactions with their hosts (i.e., endophytic

65 continuum; Schultz and Boyle, 2005).

66 Regardless of ecological mode, the evolutionary benefits of endophytic leaf colonization

67 for species that do not form fruiting bodies on leaves remains obscure. For instance, a number of

68 genotypes closely related to wood decomposers have been found to also inhabit living leaves as

69 endophytes (Promputtha et al., 2007), yet these taxa have not been observed to also form fruiting

70 bodies on leaves. Thus, it has been proposed that endophytic colonization may represent an

71 evolutionary "dead-end" (i.e., saprotrophs found as endophytes are unlikely to reproduce from

72 leaves). This idea appears logical since most endophyte infections in living leaves remain

73 localized, occupying only one or a few host plant cells (Carroll, 1988; Bayman et al., 1998;

74 Arnold \& Lutzoni, 2007), and endophytes do not usually colonize woody stems from the leaves

75 where the infection could result in fruiting body formation (Sun et al., 2012; Tateno et al., 2015;

76 Thomas et al., 2019). Yet, the colonization of live plant tissues requires specialized chemical and

77 physical systems (Kusari, Hertweck \& Spiteller, 2012) and the construction of such cellular

78 mechanisms during development, along with propagule loss, incurs evolutionary costs that are 
79

80

81

82

84

85

86

87

unaccompanied by benefits if endophytism is truly a 'dead end' for these fungi.

One possible explanation for this discrepancy is the Foraging Ascomycete (FA) hypothesis (Carroll, 1999; Thomas \& Vandegrift et al., 2016; Thomas et al., 2019; Thomas, Vandegrift \& Roy, 2017), which proposes that the function of leaf endophytism for some fungi may be to increase dispersal to other substrates by helping to bridge spatiotemporal gaps in preferred substrate. While some saprotrophic endophytes can fruit directly from fallen leaves (Sherwood-Pike, Stone \& Carroll, 1986; Osono, 2006; Peršoh et al., 2013), the FA hypothesis proposes that after leaves senesce and fall, leaf endophytes are capable of transferring to other substrates in their environment that are separate from their original endophytic hosts. Thus, during times of suboptimal environmental conditions, endophytes may have an increased likelihood of survival compared to spores or saprobic mycelia because the highly buffered environment of living leaves, which can provide a source of nutrients regardless of surrounding environmental conditions (Thomas \& Vandegrift et al., 2016). We hypothesize that the ability of spores to colonize living leaves is essentially a form of evolutionary bet-hedging that "reduces the temporal variance in fitness at the expense of a lowered arithmetic mean fitness" (Ripa, Olofsson \& Jonzén, 2010). Direct spore dispersal by itself may result in a higher mean success rate in colonizing substrates suitable for fruiting body production, but success will be highly contingent on suitable environmental conditions (Thomas, Vandegrift \& Roy, 2017). Thus, when a subset of spores from each sporulation event colonize leaves as endophytes, a species can decrease the variance of dispersal success (Thomas \& Vandegrift et al., 2016).

To encompass the processes described by the FA hypotheses, we introduce the new term viaphyte to refer to fungi that undergo these lifestyle shifts: the subset of endophytic fungi that are primarily saprotrophic, but which also occur as leaf endophytes and are capable of dispersal 
102 from their endophytic hosts to other substrates following leaf senescence. We create this term

103 because (1) referring to such fungi as "foragers" is vague and leads to confusion, and (2)

104 referring to them as "foraging ascomycetes" (or "FA utilizing fungi" and other such

105 permutations) is inaccurate as endophytes in the Basidiomycota are likely to utilize this dispersal

106 strategy as well (Thomas, Vandegrift \& Roy, 2017). "Viaphyte" joins the word via — defined as

107 "travelling through a place en route to a destination" — with the suffix, phyte, which denotes a

108 plant. In this study, we use the term specifically to refer to fungi that display the ability to

109 directly transfer from an endophytic state (inhabiting living leaf tissue, necessarily biotrophic) to

110 a free-living state (inhabiting a dead woody substrate, necessarily saprotrophic) though hyphal

111 growth.

112 While viaphytism is superficially similar to latent saprotrophism, it is a distinct and more

113 complex process. Latent saprotrophy presupposes that the purpose of a fungus being present as

114 an endophyte is to consume the tissue of its host after senescence. The idea that endophytism

115 may be a vehicle, rather than an end destination, is a distinct concept. As such, the use of the

116 term "viaphyte" helps to clarify this distinction and avoid confusion as the literature around these

117 topics evolves.

118 For the FA hypothesis to be feasible (i.e., for viaphytism to occur) it must be shown that

119 transfer from living leaves to another substrate is possible. Thomas and Vandegrift et al. (2016)

120 observed such transfer, but that study was restricted to a single fungal genus, Xylaria, and it is

121 unclear how prevalent this ability is among fungal endophytes of other taxonomic groups. Here,

122 we conducted a survey of the viaphytic abilities of endophytes present in leaves of the tropical

123 tree, Nectandra lineatifolia, as the tropics represent a hotspot for endophyte diversity (Arnold \&

124 Lutzoni, 2007). We also assessed the overall diversity of observed viaphytes and the presumed 
125 ecological roles of each isolated viaphytic fungus. Leaf endophytes are hyperdiverse and have a

126 wide taxonomic breadth (Arnold et al., 2000; Bazzicalupo, Bálint \& Schmitt, 2013; Thomas et

127 al., 2019). As a subset of the endophytic community, we expected that viaphytes would also

128 represent a wide taxonomic breadth. Despite the fact that source communities were likely to

129 harbor many biotrophs capable of facultative saprotrophy, based on the framework of the FA

130 hypothesis we hypothesized that the majority of viaphytes isolated would be taxa whose primary

131 nutritional mode is saprotrophy.

132 


\section{Materials and Methods}

\section{Culture Methods}

135 Twelve evergreen leaves of a randomly selected tree (Lauraceae; Nectandra lineatifolia

136 (Ruiz \& Pav.) Mez) were collected in an Ecuadorian cloud forest. The tree was within Reserva

137 Los Cedros, which is on the western slope of the Andes in northwestern Ecuador $\left(00^{\circ} 18031.000\right.$

$\left.138 \mathrm{~N}, 78^{\circ} 46044.600 \mathrm{~W}\right)$, at $1200 \mathrm{~m}$ above sea level. Eight $2-\mathrm{cm}^{2}$ sections were cut from each leaf

139 and surface-sterilized by successive immersion in $70 \%$ ethanol for one min, $5 \%$ sodium

140 hypochlorite (equivalent to full strength bleach) for two min, then rinsed in sterile water. The

141 leaf sections were placed onto twice-autoclaved white birch (Betula papyrifera Marshall) tongue

142 depressors (Puritan, Guilford, Maine, U.S.A.) as a standardized angiosperm woody substrate.

143 The sections from each leaf were split between two tongue depressors ( 4 sections each) resulting

144 in a total of 24 tongue depressors. These were incubated in three 95\% EtOH-sterilized Ziploc

145 storage boxes (eight in each box) at the field station in ambient temperature for six weeks. Each

146 box contained an open container of twice-autoclaved water to maintain humidity. The incubation

147 period provided opportunity for the endophytic fungi in the leaves to colonize the wood. After

148 incubation, the sticks were placed into airtight, sterile bags and brought to the University of

149 Oregon.

$150 \quad$ Fungal cultures were isolated from the inoculated wood by breaking 15 small fragments

151 ( $\sim 5 \mathrm{~mm}^{2}$ each) of wood from each tongue depressor using flame-sterilized tools and dispersing

152 them evenly among five $100 \mathrm{~mm}$ water agar plates. The ends of growing hyphae were excised

153 from the agar using a dissecting microscope and a scalpel and transferred onto nutrient plates

154 (MEA, 2\% maltose) over a two-month period. Cultures were also made from several fruiting

155 structures that grew directly from the birch substrate fragments. After a growth period of seven 
156 or more days the isolates were grouped into morphotypes (Lacap, Hyde \& Liew, 2003) at the

157 genus level based on macro- and microscopic features.

158 All field work was done with the approval of the Ecuadorian Ministry of the Environment

159 (Ministerio del Ambiente de Ecuador, Permit No. 03-2011-IC-FLO-DPAI/MA).

160 Identification of Viaphytes

161 A single representative of each morphotype was subcultured in liquid media (2\% malt

162 extract) for DNA extraction using the Qiagen DNeasy Plant kit following the manufacturer's

163 instructions, and the ITS region (the standard "barcode" locus for fungi; Schoch et al., 2012) was

164 amplified using the fungal-specific primer set ITS1F (5'-CTTGGTCATTTAGAGGAAGTAA-

165 3') and ITS4 (5'-TCCTCCGCTTATTGATATGC-3') (White et al., 1990), or in cases where

166 those primers were ineffective, isolates were amplified with ITS5 (5'-

167 GGAAGTAAAAGTCGTAACAAGG-3') and LR3 (5'-CCGTGTTTCAAGACGGG-3')

168 primers. DNA amplification was conducted with $12.5-\mu \mathrm{L}$ reaction volumes $(2.5 \mu \mathrm{L}$ of template,

$1696.25 \mu \mathrm{L}$ of Sigma Aldrich JumpstartTM Taq ReadymixTM, $2.75 \mu \mathrm{L}$ sterile water, $0.5 \mu \mathrm{L} 25 \mathrm{mM}$

$170 \mathrm{MgCl}_{2}$, and $0.25 \mu \mathrm{L}$ of each primer at $10 \mu \mathrm{M}$ ). PCR amplification was performed with an MJ

171 Research PTC-200 DNA Engine thermal cycler under the following parameters: initial

172 denaturation at $95^{\circ} \mathrm{C}$ for $2 \mathrm{~min}$, five cycles of denaturation at $95^{\circ} \mathrm{C}$ for $30 \mathrm{~s}$, annealing at $60^{\circ} \mathrm{C}$ for

$17330 \mathrm{~s}$, and extension at $72^{\circ} \mathrm{C}$ for $1 \mathrm{~min}$; followed by 25 cycles of denaturation of $95^{\circ} \mathrm{C}$ for $30 \mathrm{~s}$,

174 annealing at $55^{\circ} \mathrm{C}$ for $30 \mathrm{~s}$, and extension at $72^{\circ} \mathrm{C}$ for $1 \mathrm{~min}$; a final extension at $72^{\circ} \mathrm{C}$ for $10 \mathrm{~min}$,

175 and a final step of indefinite duration at $4{ }^{\circ} \mathrm{C}$. PCR products were visualized on a $1 \%$ agarose gel.

176 Samples were then frozen until shipping for sequencing at Functional Biosciences, Inc (Madison,

177 WI, U.S.A.) on ABI 3730xl instruments using Big Dye V3.1. ITS amplicons were sequenced bi-

178 directionally, then assembled into contigs, and manually edited in Geneious (v6.0.3; Biomatters 
179 Limited, Auckland, New Zealand) to remove priming sites and resolve mismatches. The

180 consensus sequences were then compared to published sequences in the UNITE database (v8.0;

181 Kõljalg et al., 2013) using the assign_taxonomy.py function from the Quantitative Insights into

182 Microbial Ecology (QIIME) pipeline (Caporaso et al., 2010). Taxa that returned species

183 assignments as "unidentified" were further examined using BLAST against the NCBI $n r$

184 database. Taxonomic identities were assigned at genus level and lower if the hit with the lowest

185 E-Value had greater than 97\% sequence identity across the entire ITS region. Sequences whose

186 hits did not match these criteria were categorized as "unidentified". Putative Xylaria species

187 were compared to our database of ITS sequences generated from authenticated material within

188 that genus at the same site (Thomas \& Vandegrift et al., 2016) and assigned to a taxon if

189 sequences had greater than $98 \%$ sequence identity. Taxa with greater than $99 \%$ sequence identity

190 were assumed to be the same taxon (i.e., OTU). All taxa with identical assignments by UNITE

191 met this criterion.

192 Functional guilds were assigned to each genus by using the FUNGuild online tool

193 (Nguyen et al., 2016), which assigns functional information to taxa in DNA datasets. If

194 functional guilds were not available in FUNGuild, they were determined based on the literature 195 wherever possible (Table S3).

\section{Statistical Methods}

197 Species richness per leaf was estimated using Chao2 and Jacknife1 estimators (Burnham

198 \& Overton, 1978; Chao, 1984; Colwell \& Coddington, 1994). Diversity was estimated between

199 all leaves, within leaves, and within boxes using Shannon's index (log base $e$ was used; Shannon,

200 1948) and Simpson's index (1-D; Simpson, 1949), and community structure was visualized using

201 non-metric multidimensional scaling (NMDS) and differences assessed with permutational 
202 multivariate analysis of variance (PerMANOVA). Data were analyzed using R Statistical

203 Software, v. 3.1.0 (R Core Team 2014), including the vegan package (Oksanen et al., 2013).

204 All scripts, data tables, and raw data (morphotype counts and sequence chromatograms)

205 is available via an open FigShare repository (Nelson et al., 2019). Edited sequences have been

206 uploaded to GenBank (accession numbers provided in Table S1).

207

208 Results

209

Diversity and Abundance of Viaphytes

210

Numerous endophytes from surface-sterilized leaves of Nectandra lineatifolia

211 successfully colonized the wood substrate: 477 fungal cultures were isolated after making the

212 initial transfer from leaves to wood. Isolates were grouped into 64 morphotypes, 62 of which

213 were successfully identified to genus ( 59 by DNA, three by morphology; Table S1). DNA

214 identification resulted in the consolidation of the morphotypes into 24 unique taxa at the genus

215 level (Table S2). The number of isolates for each taxon varied widely, such that $57 \%$ of the

216 isolates were represented by just two genera (i.e., Trichoderma and Penicillium), and seven of

217 the taxa were isolated only a single time (Fig. 1). In addition to hyphal growth from the wood

218 substrates, anamorphic fruiting structures were observed growing out of five stick fragments

219 originating from two leaves (Fig. S1). These isolates were identified as Xylaria flabelliformis

220 using DNA extracted from stromatic tissues. Including $X$. flabelliformis, we observed a total of

22124 viaphytic taxa, which were identified to the genus level (Fig. 1). Additionally, we observed

222 that the majority of the woody substrate fragments displayed a dramatic decrease in substrate

223 volume that may be explained by high levels of cell wall degrading enzymes typical of white-rot

224 fungi. However, we did not attempt to determine which taxa were responsible for this dramatic 
225 reduction in volume.

226 The species accumulation curve did not reach a saturation point, suggesting

227 that the full richness of viaphytes from these leaves was not isolated (Fig. 2). Estimates of actual

228 species richness ranged from 36.5 (first order jackknife, $S E=4.1$ ) to 42.3 (chao2, $S E=13.8$ ).

Viaphyte communities within incubation boxes were more similar to each other than to

230 communities from other boxes (PerMANOVA: $F_{1,23}=6.34, p=0.001$ ), whereas communities

231 from sticks that were inoculated by the same leaves were not more similar to each other than to

232 sticks inoculated from different leaves (PerMANOVA: $F_{1,23}=1.04, p=0.404$; Fig. 3). Isolates

233 representing the four most common taxa were concentrated in common boxes, with $100 \%$ of

234 Neopestalotiopsis foedans in Box 1 (44 total isolates across all boxes), 96\% of Paecilomyces

235 formosus in Box 1 (75 total isolates), 87\% of Trichoderma spp. in Box 2 (89 total isolates), and

236 61\% of Penicillium spp. in Box 3 (179 total isolates).

\section{Taxonomic Distribution}

The higher order taxonomic ranks in our samples included two phyla, five classes, twelve

orders, and nineteen families (Table S2). Although Ascomycota was the dominant phylum, both

240 in terms of number of taxa and total number of isolates ( $73 \%$ and $94 \%$, respectively), isolates of

241 Basidiomycota also were obtained in culture. Among Ascomycota fungi, Sordariomycetes were

242 the most common class in terms of number of taxa (38.4\% of total taxa), whereas fungi in the

243 Eurotiomycetes, driven by the frequency of Penicillium spp., represented more than half of the

244 isolates (55.7\%). At the ordinal level, the most common orders among all taxa were Xylariales

245 (Sordariomycetes, Ascomycota) and Polyporales (Basidiomycta) (each representing 19.2\% of all

246 taxa). Isolates of Eurotiales (Eurotiomycetes, Ascomycota), again driven by Penicillium spp.,

247 represented the most isolates (55.1\% of all isolates). 


\section{Functional Guilds}

249 The FUNGuild database contained putative functional guilds for all but two of the genera

250 we isolated as viaphytes. The first unassigned genus, Alloconiothyrium, is newly described and

251 presently represented by a single species, $A$. aptrootii, which was isolated from a soil sample in

252 Papua New Guinea (Verkley et al. 2014). We therefore did not assign it to a functional guild

253 since so little information is available. The second, Neopestalotiopsis, we classified as a "plant

254 pathogen/saprotroph" based on substrates listed in species descriptions (Maharachchikumbura et

255 al. 2014). The viaphyte genera of our study fit into three distinct functional guilds: saprotroph,

256 plant pathogen, and plant pathogen/saprotroph. Saprotroph was the dominant functional guild in

257 terms of number of genera $(70.8 \% ; 17$ out of 24$)$ and number of isolates $(82.3 \%, 389$ out of 467$)$.

258 Four of the genera were classified as plant pathogens (16.7\%) and three genera were classified as

259 plant pathogen/saprotrophs (12.5\%). Of the isolates, 64 were classified as plant

260 pathogen/saprotrophs (13.7\%) and fourteen were classified as plant pathogens (3.0\%).

261

262 


\section{Discussion}

\section{Viaphyte Prevalence}

265 Here, we demonstrate for the first time that a diverse array of tropical leaf endophytes can

266 colonize woody substrates through direct contact with leaves, thus representing an ability to

267 alternate between endophytic and saprotrophic life stages. Our results show that viaphytes are

268 commonplace and multiple fungal species have a potential for viaphytic dispersal from within

269 each leaf, even though it is likely that we underestimate richness due to the biases of culture-

270 based studies (Schmit \& Lodge, 2005) and the incompleteness of our sequencing efforts. The

271 high frequency of viaphytic colonization suggests that the underlying mechanisms are likely

272 mechanistically straightforward (i.e., as simple as hyphae extending from one substrate into the

273 other), although the enzymatic potential to successfully colonize woody substrates may be taxon-

274 dependent.

275 While the present viaphyte survey examined only a single tree of Nectandra lineatifolia,

276 it seems unlikely that this host is unique in allowing the transfer of endophytes to woody

277 substrates, or that the viaphytes observed within its tissues are only able to transfer from this

278 particular host. In other words, if the host tree and its endophytic symbionts are taken to

279 represent what is typical for a broad-leaved tropical tree, it follows that viaphytes are likely

280 commonplace symbionts in the leaves of tropical forests. Other studies that have demonstrated

281 the high abundance of endophytes in tropical forests corroborate this potential (Arnold \&

282 Lutzoni, 2007; Rodriguez et al., 2009; Thomas \& Vandegrift et al., 2016; Del Olmo-Ruiz \&

283 Arnold, 2017; Roy \& Banerjee, 2018).

284 Yet even if fungi with viaphytic abilities are common, the extent to which viaphytic

285 colonization events occur in natural systems is unknown. While we placed leaves containing 
286 endophytes on sterile wood substrates, viaphytes in nature would face competition from other

287 sources of colonization, such as spores or saprotrophs already present in the wood (Thomas \&

288 Vandegrift et al., 2016). Future experiments should empirically test the ability of viaphytic fungi

289 to successfully colonize such diverse woody substrates in the face of competition. It is likely that

290 viaphytism and direct spore colonization each have their own set of advantages. For instance, it

291 is possible that the carbon and water supplies inherent in leaf tissues give an advantage to

292 viaphytic dispersal as compared to spores, especially if conditions are dry or otherwise

293 unsuitable for spore germination. In addition, leaves could trap moisture between the leaf and

294 substrate, and may act as barriers that exclude competing spores from being deposited on the

295 woody substrate surfaces (Thomas \& Vandegrift et al., 2016). Certainly, direct spore dispersal

296 has its own advantages in the form of reduced complexity (i.e., no intermediate colonization

297 stage is required), increased potential travel distance via air currents (McCartney \& West, 2007;

298 Calhim et al., 2018), and much greater abundances compared to leaf-born colonies. These ideas

299 were previously explored by (Thomas, Vandegrift \& Roy, 2017) using a simple agent-based

300 model. As predicted by Thomas \& Vandegrift et al. (2016), in these simulations viaphytism is

301 advantageous under adverse conditions given retention of endophyte infections and at least some

302 trees on the landscape.

303 The viaphyte community of Nectandra lineatifolia was characterized by a few taxa with

304 high abundances and a large number of taxa with low abundances (Fig. 2). While this pattern is

305 typical for culturable studies of leaf endophytes (Arnold et al., 2000, 2007; Vega et al., 2010;

306 Gazis \& Chaverri, 2010; Ikeda et al., 2014; Del Olmo-Ruiz \& Arnold, 2017), some patterns in

307 the data suggest that they are partly due to methodological biases. For instance, Penicillium spp.

308 and Trichoderma spp. were both observed to be fast growing in culture in this study, and culture- 
309 based studies are known to be biased for faster-growing taxa (Kirk et al., 2004). Also, given that

310 each of the four most dominant taxa had a disproportionately high number of isolates

311 concentrated in a single box, these dominant taxa likely colonized the sticks within their

312 respective boxes via sporulation during the inoculation period (Fig. 3). All four of these

313 dominant taxa readily produced a high quantity of conidia in culture. Therefore, the number of

314 isolates for these abundant taxa should be interpreted with caution as they likely do not reflect

315 the actual abundance in host leaves, but rather comparatively fast growth and within-box

316 contamination. It is also notable that our experiment did not have a true negative control, without

317 an inoculation source, to account for true contaminants (i.e., taxa that may have originated

318 outside of the leaves). While it is possible that some taxa detected may have been contaminants,

319 there are several factors which suggest relatively low rates of outside contamination: (1) the

320 thorough sterilization procedures we employed; (2) the high endophyte load in the tropics

321 (Arnold et al., 2000; Arnold \& Lutzoni, 2007); (3) the near ubiquity of detected taxa being found

322 in tropical endophyte datasets; and (4) the restriction of common taxa to single boxes.

323 Ecological Strategies

324 It is well documented that many endophytes have a much broader host range in the

325 endophytic state than as saprotrophs - e.g., Xylariaceae, the majority of which do not typically

326 reproduce in the litter (Davis et al., 2003; Peršoh et al., 2010; U'Ren et al., 2016). It is, in fact,

327 apparently common for such endophytes to be present in the leaves of hosts upon whose wood

328 they never fruit (Carroll \& Carroll, 1978; Peršoh et al., 2010; Unterseher, Peršoh \& Schnittler,

329 2013). This is evidence for a Foraging Ascomycete ecology, since latent saprotrophism is

330 excluded as a strategy for species which are incapable of fruiting out of leaves (Thomas \&

331 Vandegrift et al., 2016). It is interesting that many fungi that are not typically observed fruiting 
332 on litter, such as members of the Xylariaceae, are well known as highly competitive litter decay

333 organisms (Koide, Osono \& Takeda, 2005; Osono, 2007; Osono et al., 2011). It is logical that

334 increased substrate utilization in the litter, and therefore increased resource accumulation,

335 translates to increased ability to compete for substrates external to the litter (Boddy, 2000).

336 Latent saprotrophism is a well-documented strategy of some leaf endophytes (Osono,

337 2006; Parfitt et al., 2010; Voříšková \& Baldrian, 2013). An excellent example of this ecological

338 strategy is the fungus Rhabdocline parkeri (Sherwood-Pike, Stone \& Carroll, 1986), which

339 spends most of its lifecycle as an endophyte in the needles of Pseudotsuga menziesii, waiting for

340 the needles to die (typically 4-5 years). After needle senescence, the fungus rapidly invades the

341 surrounding needle tissues (often before they are even shed), and then produces its conidial state,

342 followed by a small perithecial teleomorph early in the winter, soon after the leaves are shed

343 (Stone, 1987). The host specificity of $R$. parkerii, and other fungi like it, is explained by the role

344 of priority effects (Chase, 2003) in the latent saprotrophic habit: while priority effects may work

345 to benefit viaphytic fungi somewhat, they serve as a strong evolutionary filter for fungi utilizing

346 a latent saprotrophic strategy. Future studies examining viaphytic ecological strategies should

347 focus on exploring the boundaries between viaphytic and latent saprotrophic ecologies.

348

349

350

351

352

353

354

\section{Taxonomic Distribution}

The viaphytes in this study belong to a wide taxonomic breadth, consisting of both Basidiomycota and Ascomycota. This implies that the benefits described by the FA hypothesis are available to members of the Basidiomycota as well, though the original idea concerned only the Ascomycota (Carroll, 1999). The taxonomic distribution of viaphytes from this study resemble those of general tropical leaf-endophytes described in other work (Arnold \& Lutzoni, 2007; Thomas \& Vandegrift et al., 2016; Roy \& Banerjee, 2018). In particular, Arnold et al. 
355 (2007) reported a similar pattern and proportion of Eurotiomycetes, Dothideomycetes, and

356 Sordariomycetes, also noting the dominance of Ascomycota.

357 The wide taxonomic distribution of viaphytes suggests that viaphytic dispersal may be a

358 deeply ancestral trait. This would parallel endophytes in general, which appear to have

359 associated with plants since at least 400 mya (Krings et al., 2007). Future taxonomic and

360 paleontological work may help inform when viaphytism emerged as a dispersal strategy within

361 the Fungi.

362 Functional Guilds

363 Most of the viaphytic taxa in our study (17 of 24 taxa) were classified by FUNGuild as

364 having saprotrophic abilities (Table S3). Many of these saprotrophic taxa are known wood-decay

365 fungi, including Xylaria spp. and Phanerochaete spp. (Nguyen et al., 2016). In addition, our host

366 leaves were harboring at least some species capable of physiological white-rot fungi, as

367 evidenced by bleaching of the wood and a substantial decrease in size in several of our substrate

368 fragments. Even some ascomyceteous molds are known to be degraders of lignin, including

369 some Penicillium spp., Trichoderma spp., and Fusarium oxysporum, all of which were present

370 among our isolates (Rodriguez et al., 1996; Ryazanova, Chuprova \& Luneva, 2015). While the

371 prevailing explanation for the occurrence of saprotrophic fungi as endophytes is that they are

372 latent saprotrophs waiting to consume leaves upon senescence (Peršoh, 2013), many taxa we

373 observed here, and others commonly isolated as endophytes, are not known to reproduce on dead

374 leaves. Alternately, such endophytic saprotrophs may represent an evolutionary 'dead-end' if

375 they are unable to escape that state (Bayman et al., 1998), but our data suggests that it may be the

376 norm for such fungi to transfer out of an endophytic state. Additionally, the presence of several

377 taxa classified as primarily pathotrophs suggests that the facultative ability to access saprotrophic 
378 lifestyles may serve as a functional bridge for certain biotrophic species. One might expect that if

379 biotrophs are cultivated on any given substrate, the resulting community would be dominated by

380 fungi that were typically biotrophic, but with facultative saprotrophic abilities. This, however, is

381 not what we find here, indicating that it is likely that a large proportion of endophytes isolated

382 here are not transitioning to saprotrophy in a facultative manner, but as a transition back to their

383 primary nutritional mode.

384 We observed several instances of fungi apparently thriving after colonizing wood. For 385 example, despite the fact that only very few, generally host-specific, Xylaria are capable of

386 fruiting from leaves (Rogers, 2000), Xylaria flabelliformis was observed fruiting directly from

387 the woody substrates after transfer from an endophytic state. Interestingly, this taxon was found

388 to be a common endophyte of forests in Taiwan (Vandegrift et al., 2019). Previously, we found

389 five Xylaria species both as endophytes and as stromata on woody substrates at Los Cedros

390 (Thomas \& Vandegrift et al., 2016). Emigration from leaves to wood is likely necessary for such

391 endophytic individuals to regain reproductive potential.

392

393 Conclusion

As an alternative to the latent saprotroph hypothesis, the FA hypothesis (viaphytism)

395

suggests that many saprotrophs use endophytism to modify dispersal to their primary (i.e.,

reproductive) substrates (Carroll, 1999; Thomas \& Vandegrift et al., 2016; Thomas, Vandegrift

$397 \&$ Roy, 2017). Here, we demonstrate for the first time that a diverse assemblage of foliar

398 endophytes can directly colonize woody substrates from leaves, and that a high proportion of

399 these fungi are ecological saprotrophs. This work provides new support for the FA hypothesis.

400 While the prevalence of viaphytic dispersal in nature is currently unknown, the diversity and 
401 abundance of viaphytes observed here suggests that it may be commonplace. Viaphytic dispersal

402 may have ramifications not only for the dispersal and competition dynamics of fungi, but also for

403 larger scale processes, such as decomposition (Thomas, Vandegrift \& Roy, 2017). These

404 dynamics are largely unexplored and represent a vast potential for future research (but see, e.g., 405 (Osono, 2006).

406 One such research topic that is suggested by this work concerns the effects of viaphytic 407 dispersal on outcrossing (and thus evolutionary trajectories) of taxa utilizing this dispersal 408 strategy. Dispersal by viaphytism could lead to an increase in outcrossing by reducing the 409 chances of mating between spores of the same parent: spores released from the same fruiting 410 event have a relatively high likelihood of colonizing the same nearby substrates and mating.

411 However, if a subset of those spores delay their colonization of wood by becoming endophytes, 412 it is likely that they increase their chances of mating with a non-sibling. 


\section{Acknowledgements}

414 DC Thomas aided with lab work and commented on the manuscript, H Soukup helped with

415 sequencing. We appreciated the facilities of the field station at Reserva Los Cedros

416 (reservaloscedros.org) in Ecuador, where the experiment took place. We are grateful to our

417 collaborators at the Ecuadorian Institute of Biodiversity (INABIO) for helping us get the

418 necessary permits to work in Ecuador through the Ministerio del Ambiente de Ecuador (No. 03-

419 2011-IC-FLO-DPAI/MA). Lastly, we are thankful for the thoughtful commentary on this

420 manuscript by the editor, an anonymous reviewer, and Naupaka Zimmerman. 


\section{Figures Legends}

422

423 Figure 1: Summary of identified fungal endophytes that transferred from host leaves into a

424 woody substrate. From 12 leaves, 25 taxa transferred to wood and were subsequently isolated.

425 Of a total of 472 identified isolates, $82 \%$ were represented by the four most common taxa. The

426 total isolates per taxa roughly corresponds to the number of leaves they were isolated from. The

427 numbers on the bars specify the number of cultures per taxon. [Note: the left axis is on a

428 logarithmic scale.] 5 isolates remained unidentified and are not included in the figure.

429

430 Figure 2: Species accumulation curve for viaphytes. The culturing did not achieve a saturation 431 of culturable viaphytic taxa.

432

433 Figure 3: Non-metric Multidimensional Scaling (NMDS) plot of viaphyte communities.

434 Each point represents an individual birch tongue depressor; lines connect sticks that were 435 inoculated with the same leaf; color indicates inoculation box.

436

437 Figure S1: photos of saprotrophic Xylaria flabelliformis stromata. Growing on wood 438 substrates inoculated by leaf endophytes.

439 


\section{References}

441 Arnold AE, Henk DA, Eells RL, Lutzoni F, Vilgalys R. 2007. Diversity and phylogenetic affinities of 442 foliar fungal endophytes in loblolly pine inferred by culturing and environmental PCR. Mycologia 443 99:185-206. DOI: 10.3852/mycologia.99.2.185.

444 Arnold AE, Lutzoni F. 2007. Diversity and host range of foliar fungal endophytes: are tropical leaves 445 biodiversity hotspots? Ecology 88:541-549. DOI: 10.1890/05-1459.

446 Arnold AE, Maynard Z, Gilbert GS, Coley PD, Kursar TA. 2000. Are tropical fungal endophytes 447 hyperdiverse? Ecology letters 3:267-274. DOI: 10.1046/j.1461-0248.2000.00159.x.

448 Barge EG, Leopold DR, Peay KG, Newcombe G, Busby PE. 2019. Differentiating spatial from environmental effects on foliar fungal communities of Populus trichocarpa. Journal of biogeography

451 Bayman P, Angulo-Sandoval P, Báez-ortiz Z, Lodge DJ. 1998. Distribution and dispersal of Xylaria 452 endophytes in two tree species in Puerto Rico. Mycological research 102:944-948. DOI: 10.1017/S095375629700590X.

Bazzicalupo AL, Bálint M, Schmitt I. 2013. Comparison of ITS1 and ITS2 rDNA in 454 sequencing of hyperdiverse fungal communities. Fungal ecology 6:102-109. DOI: 10.1016/j.funeco.2012.09.003.

Boddy L. 2000. Interspecific combative interactions between wood-decaying basidiomycetes. FEMS microbiology ecology 31:185-194. DOI: 10.1111/j.1574-6941.2000.tb00683.x.

Burnham KP, Overton WS. 1978. Estimation of the size of a closed population when capture probabilities vary among animals. Biometrika 65:625-633. DOI: 10.1093/biomet/65.3.625.

460 Calhim S, Halme P, Petersen JH, Læssøe T, Bässler C, Heilmann-Clausen J. 2018. Fungal spore diversity 461 reflects substrate-specific deposition challenges. Scientific reports 8:5356. DOI: 10.1038/s41598$462 \quad 018-23292-8$.

463 Caporaso JG, Kuczynski J, Stombaugh J, Bittinger K, Bushman FD, Costello EK, Fierer N, Pena AG, 464 Goodrich JK, Gordon JI. 2010. QIIME allows analysis of high-throughput community sequencing 
465 data. Nature methods 7:335-336.

466 Carroll G. 1988. Fungal endophytes in stems and leaves: from latent pathogen to mutualistic symbiont.

467 Ecology 69:2-9. DOI: 10.2307/1943154.

468 Carroll GC. 1999. The foraging ascomycete. In: 16th International Botanical Congress, Abstracts. Saint 469 Louis, MO, USA,.

470 Carroll GC, Carroll FE. 1978. Studies on the incidence of coniferous needle endophytes in the Pacific 471 Northwest. Canadian journal of botany. Journal canadien de botanique 56:3034-3043.

472 Carroll G, Petrini O. 1983. Patterns of substrate utilization by some fungal endophytes from coniferous 473 foliage. Mycologia:53-63.

474 Chao A. 1984. Nonparametric Estimation of the Number of Classes in a Population. Scandinavian journal 475 of statistics, theory and applications 11:265-270.

476 Chase JM. 2003. Community assembly: when should history matter? Oecologia 136:489-498. DOI:

477 10.1007/s00442-003-1311-7.

478

479

480

481

482

483

484

485

486

487

488

489

490

Clay K. 1988. Fungal Endophytes of Grasses: A Defensive Mutualism between Plants and Fungi. Ecology 69:10-16. DOI: 10.2307/1943155.

Colwell RK, Coddington JA. 1994. Estimating terrestrial biodiversity through extrapolation. Philosophical transactions of the Royal Society of London. Series B, Biological sciences 345:101118. DOI: $10.1098 /$ rstb.1994.0091.

Davis EC, Franklin JB, Shaw AJ, Vilgalys R. 2003. Endophytic Xylaria (Xylariaceae) among liverworts and angiosperms: phylogenetics, distribution, and symbiosis. American journal of botany 90:16611667. DOI: 10.3732/ajb.90.11.1661.

Del Olmo-Ruiz M, Arnold AE. 2017. Community structure of fern-affiliated endophytes in three neotropical forests. Journal of tropical ecology 33:60-73. DOI: 10.1017/S0266467416000535.

Gazis R, Chaverri P. 2010. Diversity of fungal endophytes in leaves and stems of wild rubber trees (Hevea brasiliensis) in Peru. Fungal ecology 3:240-254. DOI: 10.1016/j.funeco.2009.12.001. Hodgson S, de Cates C, Hodgson J, Morley NJ, Sutton BC, Gange AC. 2014. Vertical transmission of 
491 fungal endophytes is widespread in forbs. Ecology and evolution 4:1199-1208. DOI:

$492 \quad 10.1002 /$ ece3.953.

493 Ikeda A, Matsuoka S, Masuya H, Mori AS, Hirose D, Osono T. 2014. Comparison of the diversity,

494 composition, and host recurrence of xylariaceous endophytes in subtropical, cool temperate, and

495 subboreal regions in Japan. Population Ecology 56:289-300.

496 Kirk JL, Beaudette LA, Hart M, Moutoglis P, Klironomos JN, Lee H, Trevors JT. 2004. Methods of

497 studying soil microbial diversity. Journal of microbiological methods 58:169-188. DOI:

$498 \quad$ 10.1016/j.mimet.2004.04.006.

499 Koide K, Osono T, Takeda H. 2005. Fungal succession and decomposition of Camellia japonica leaf

$500 \quad$ litter. Ecological research 20:599-609. DOI: 10.1007/s11284-005-0077-2.

501 Kõljalg U, Nilsson RH, Abarenkov K, Tedersoo L, Taylor AFS, Bahram M, Bates ST, Bruns TD,

502 Bengtsson-Palme J, Callaghan TM. 2013. Towards a unified paradigm for sequence-based

503 identification of fungi. Molecular ecology 22:5271-5277.

504 Krings M, Taylor TN, Hass H, Kerp H, Dotzler N, Hermsen EJ. 2007. Fungal endophytes in a 400-

505 million-yr-old land plant: infection pathways, spatial distribution, and host responses. The New

$506 \quad$ phytologist 174:648-657.

507 Kusari S, Hertweck C, Spiteller M. 2012. Chemical ecology of endophytic fungi: origins of secondary

508 metabolites. Chemistry \& biology 19:792-798. DOI: 10.1016/j.chembiol.2012.06.004.

509 Lacap DC, Hyde KD, Liew ECY. 2003. An evaluation of the fungal "morphotype" concept based on

$510 \quad$ ribosomal DNA sequences. Fungal diversity 12:53-66.

511 Martins F, Pereira JA, Bota P, Bento A, Baptista P. 2016. Fungal endophyte communities in above- and

512 belowground olive tree organs and the effect of season and geographic location on their structures.

$513 \quad$ Fungal ecology 20:193-201. DOI: 10.1016/j.funeco.2016.01.005.

514 McCartney A, West J. 2007. Dispersal of fungal spores through the air. In: Food Mycology. CRC press, 515 79-96.

516 Nelson A, Vandegrift R, Carroll GC, Roy BA. 2019. Data from: Double Lives: Transfer of fungal 
517 endophytes from leaves to woody substrates. DOI: 10.6084/m9.figshare.9794699.v1.

518 Nguyen NH, Song Z, Bates ST, Branco S, Tedersoo L, Menke J, Schilling JS, Kennedy PG. 2016.

519 FUNGuild: An open annotation tool for parsing fungal community datasets by ecological guild.

$520 \quad$ Fungal ecology 20:241-248. DOI: 10.1016/j.funeco.2015.06.006.

521 Oksanen J, Blanchet FG, Kindt R, Legendre P, Minchin PR, O’Hara RB, Simpson GL, Solymos P,

522 Stevens MHH, Wagner H. 2013. Package “vegan.” R Packag ver 254:20-8.

523 Osono T. 2006. Role of phyllosphere fungi of forest trees in the development of decomposer fungal

524 communities and decomposition processes of leaf litter. Canadian journal of microbiology 52:701-

$525 \quad 716$.

526 Osono T. 2007. Ecology of ligninolytic fungi associated with leaf litter decomposition. Ecological 527 research 22:955-974.

528 Osono T, Takeda H. 1999. Decomposing ability of interior and surface fungal colonizers of beech leaves with reference to lignin decomposition. European journal of soil biology 35:51-56. DOI:

530 10.1016/S1164-5563(99)00112-0.

531 Osono T, To-Anun C, Hagiwara Y, Hirose D. 2011. Decomposition of wood, petiole and leaf litter by 532 Xylaria species from northern Thailand. Fungal ecology 4:210-218. DOI:

$533 \quad 10.1016 /$ j.funeco.2010.11.003.

534 Parfitt D, Hunt J, Dockrell D, Rogers HJ, Boddy L. 2010. Do all trees carry the seeds of their own 535 destruction? PCR reveals numerous wood decay fungi latently present in sapwood of a wide range of 536 angiosperm trees. Fungal ecology 3:338-346. DOI: 10.1016/j.funeco.2010.02.001.

537 Peršoh D. 2013. Factors shaping community structure of endophytic fungi-evidence from the Pinus538 Viscum-system. Fungal diversity 60:55-69. DOI: 10.1007/s13225-013-0225-x.

539 Peršoh D, Melcher M, Flessa F, Rambold G. 2010. First fungal community analyses of endophytic 540 ascomycetes associated with Viscum album ssp. austriacum and its host Pinus sylvestris. Fungal 541 biology 114:585-596. DOI: 10.1016/j.funbio.2010.04.009.

542 Peršoh D, Segert J, Zigan A, Rambold G. 2013. Fungal community composition shifts along a leaf 
543 degradation gradient in a European beech forest. Plant and soil 362:175-186. DOI: 10.1007/s11104544 012-1271-y.

545 Porras-Alfaro A, Bayman P. 2011. Hidden fungi, emergent properties: endophytes and microbiomes.

546 Annual review of phytopathology 49:291-315. DOI: 10.1146/annurev-phyto-080508-081831.

547 Promputtha I, Lumyong S, Dhanasekaran V, McKenzie EHC, Hyde KD, Jeewon R. 2007. A phylogenetic 548 evaluation of whether endophytes become saprotrophs at host senescence. Microbial ecology 53:579-590.

Ripa J, Olofsson H, Jonzén N. 2010. What is bet-hedging, really? Proceedings. Biological sciences / The Royal Society 277:1153-1154. DOI: 10.1098/rspb.2009.2023.

Rodriguez A, Perestelo F, Carnicero A, Regalado V, Perez R, de la Fuente G, Falcon MA. 1996.

553

554

555

556

557

558

559

560

561

562

563

564

565

566

567 Degradation of natural lignins and lignocellulosic substrates by soil-inhabiting fungi imperfecti. FEMS microbiology ecology 21:213-219. DOI: 10.1111/j.1574-6941.1996.tb00348.x.

Rodriguez RJ, White JF Jr, Arnold AE, Redman RS. 2009. Fungal endophytes: diversity and functional roles. The New phytologist 182:314-330. DOI: 10.1111/j.1469-8137.2009.02773.x.

Rogers JD. 2000. Thoughts and musings on tropical Xylariaceae. Mycological research 104:1412-1420. DOI: $10.1017 / \mathrm{S} 0953756200003464$.

Roy S, Banerjee D. 2018. Diversity of Endophytes in Tropical Forests. In: Pirttilä AM, Frank AC eds. Endophytes of Forest Trees: Biology and Applications. Cham: Springer International Publishing, 4362. DOI: 10.1007/978-3-319-89833-9_3.

Ryazanova TV, Chuprova NA, Luneva TA. 2015. Effect of Trichoderma fungi on lignin from tree species barks. Catalysis in Industry 7:82-89. DOI: 10.1134/S2070050415010134.

Schmit JP, Lodge DJ. 2005. Classical methods and modern analysis for studying fungal diversity. Mycology Series.

Schoch CL, Seifert KA, Huhndorf S, Robert V, Spouge JL, Levesque CA, Chen W, Bolchacova E, Voigt K, Crous PW, Miller AN, Wingfield MJ, Aime MC, An K-D, Bai F-Y, Barreto RW, Begerow D, Bergeron M-J, Blackwell M, Boekhout T, Bogale M, Boonyuen N, Burgaz AR, Buyck B, Cai L, Cai 
569 Q, Cardinali G, Chaverri P, Coppins BJ, Crespo A, Cubas P, Cummings C, Damm U, Beer ZW de,

570 Hoog GS de, Del-Prado R, Dentinger B, Diéguez-Uribeondo J, Divakar PK, Douglas B, Dueñas M,

571 Duong TA, Eberhardt U, Edwards JE, Elshahed MS, Fliegerova K, Furtado M, García MA, Ge Z-W,

572 Griffith GW, Griffiths K, Groenewald JZ, Groenewald M, Grube M, Gryzenhout M, Guo L-D,

573 Hagen F, Hambleton S, Hamelin RC, Hansen K, Harrold P, Heller G, Herrera C, Hirayama K,

574 Hirooka Y, Ho H-M, Hoffmann K, Hofstetter V, Högnabba F, Hollingsworth PM, Hong S-B,

575 Hosaka K, Houbraken J, Hughes K, Huhtinen S, Hyde KD, James T, Johnson EM, Johnson JE,

576 Johnston PR, Jones EBG, Kelly LJ, Kirk PM, Knapp DG, Kõljalg U, Kovács GM, Kurtzman CP,

577 Landvik S, Leavitt SD, Liggenstoffer AS, Liimatainen K, Lombard L, Luangsa-ard JJ, Lumbsch HT,

578 Maganti H, Maharachchikumbura SSN, Martin MP, May TW, McTaggart AR, Methven AS, Meyer

579 W, Moncalvo J-M, Mongkolsamrit S, Nagy LG, Nilsson RH, Niskanen T, Nyilasi I, Okada G,

580 Okane I, Olariaga I, Otte J, Papp T, Park D, Petkovits T, Pino-Bodas R, Quaedvlieg W, Raja HA,

581 Redecker D, Rintoul TL, Ruibal C, Sarmiento-Ramírez JM, Schmitt I, Schüßler A, Shearer C,

582 Sotome K, Stefani FOP, Stenroos S, Stielow B, Stockinger H, Suetrong S, Suh S-O, Sung G-H,

583 Suzuki M, Tanaka K, Tedersoo L, Telleria MT, Tretter E, Untereiner WA, Urbina H, Vágvölgyi C,

584 Vialle A, Vu TD, Walther G, Wang Q-M, Wang Y, Weir BS, Weiß M, White MM, Xu J, Yahr R,

585 Yang ZL, Yurkov A, Zamora J-C, Zhang N, Zhuang W-Y, Schindel D. 2012. Nuclear ribosomal

586 internal transcribed spacer (ITS) region as a universal DNA barcode marker for Fungi. Proceedings

587 of the National Academy of Sciences of the United States of America 109:6241-6246. DOI:

$588 \quad 10.1073 /$ pnas.1117018109.

589 Shannon CE. 1948. A Mathematical Theory of Communication. Bell System Technical Journal 27:379-

590 423. DOI: $10.1002 /$ j.1538-7305.1948.tb01338.x.

591 Sherwood-Pike M, Stone JK, Carroll GC. 1986. Rhabdocline parkeri, a ubiquitous foliar endophyte of

592 Douglas-fir. Canadian journal of botany. Journal canadien de botanique 64:1849-1855.

593 Simpson EH. 1949. Measurement of Diversity. Nature 163:688-688. DOI: 10.1038/163688a0.

594 Slippers B, Wingfield MJ. 2007. Botryosphaeriaceae as endophytes and latent pathogens of woody plants:

Peer] reviewing PDF | (2019:09:41125:3:1:CHECK 15 May 2020) 
diversity, ecology and impact. Fungal biology reviews 21:90-106. DOI: 10.1016/j.fbr.2007.06.002.

596 Stone JK. 1987. Initiation and development of latent infections by Rhabdocline parkeri on Douglas-fir.

597 Canadian journal of botany. Journal canadien de botanique 65:2614-2621.

598 Stone JK, Bacon CW, White JF Jr. 2000. An overview of endophytic microbes: endophytism defined. In:

599 Microbial endophytes. CRC Press, 17-44. DOI: 10.1201/9781482277302-1.

600 Sun Y, Wang Q, Lu X, Okane I, Kakishima M. 2012. Endophytic fungal community in stems and leaves

601 of plants from desert areas in China. Mycological progress 11:781-790. DOI: 10.1007/s11557-011-

$602 \quad$ 0790-x.

603 Szink I, Davis EL, Ricks KD, Koide RT. 2016. New evidence for broad trophic status of leaf endophytic

604 fungi of Quercus gambelii. Fungal ecology 22:2-9. DOI: 10.1016/j.funeco.2016.04.003.

605 Tateno O, Hirose D, Osono T, Takeda H. 2015. Beech cupules share endophytic fungi with leaves and 606 twigs. Mycoscience 56:252-256. DOI: 10.1016/j.myc.2014.07.005.

607 Thomas DC, Vandegrift R, Ludden A, Carroll GC, Roy BA. 2016. Spatial Ecology of the Fungal Genus 608 Xylaria in a Tropical Cloud Forest. Biotropica 48:381-393. DOI: 10.1111/btp.12273.

609 Thomas DC, Vandegrift R, Roy B. 2017. An agent-based model of the Foraging Ascomycete Hypothesis. 610 bioRxiv.

611 Thomas D, Vandegrift R, Roy BA, Hsieh H-M, Ju Y-M. 2019. Spatial patterns of fungal endophytes in a 612 subtropical montane rainforest of northern Taiwan. Fungal ecology 39:316-327. DOI:

$613 \quad$ 10.1016/j.funeco.2018.12.012.

614 Unterseher M, Peršoh D, Schnittler M. 2013. Leaf-inhabiting endophytic fungi of European Beech (Fagus 615 sylvatica L.) co-occur in leaf litter but are rare on decaying wood of the same host. Fungal diversity 616 60:43-54. DOI: 10.1007/s13225-013-0222-0.

617 U'Ren JM, Arnold AE. 2016. Diversity, taxonomic composition, and functional aspects of fungal 618 communities in living, senesced, and fallen leaves at five sites across North America. PeerJ 4:e2768. 619 DOI: $10.7717 /$ peerj.2768.

620 U'Ren JM, Miadlikowska J, Zimmerman NB, Lutzoni F, Stajich JE, Arnold AE. 2016. Contributions of 
621 North American endophytes to the phylogeny, ecology, and taxonomy of Xylariaceae

622 (Sordariomycetes, Ascomycota). Molecular phylogenetics and evolution 98:210-232. DOI:

$623 \quad 10.1016 /$ j.ympev.2016.02.010.

624 Vandegrift R, Thomas DC, Ju Y-M, Soukup H, Carroll GC, Roy BA. 2019. Spatial ecology of

625 endophytes in Taiwan: combining traditional collection and next-generation sequence-based

626 microbial survey techniques. Mycologia.

627 Vega FE, Simpkins A, Aime MC, Posada F, Peterson SW, Rehner SA, Infante F, Castillo A, Arnold AE.

628 2010. Fungal endophyte diversity in coffee plants from Colombia, Hawai’i, Mexico and Puerto Rico.

$629 \quad$ Fungal ecology 3:122-138.

630 Voříšsová J, Baldrian P. 2013. Fungal community on decomposing leaf litter undergoes rapid

631 successional changes. The ISME journal 7:477-486. DOI: 10.1038/ismej.2012.116.

632 White TJ, Bruns T, Lee S, Taylor JW. 1990. Amplification and direct sequencing of fungal ribosomal

633 RNA genes for phylogenetics. PCR protocols: a guide to methods and applications 18:315-322. 
Figure 1

Summary of identified fungal endophytes that transferred from host leaves into a woody substrate.

From 12 leaves, 25 taxa transferred to wood and were subsequently isolated. Of a total of 472 identified isolates, $82 \%$ were represented by the four most common taxa. The total isolates per taxa roughly corresponds to the number of leaves they were isolated from. The numbers on the bars specify the number of cultures per taxon. [Note: the left axis is on a logarithmic scale.] 5 isolates remained unidentified and are not included in the figure.

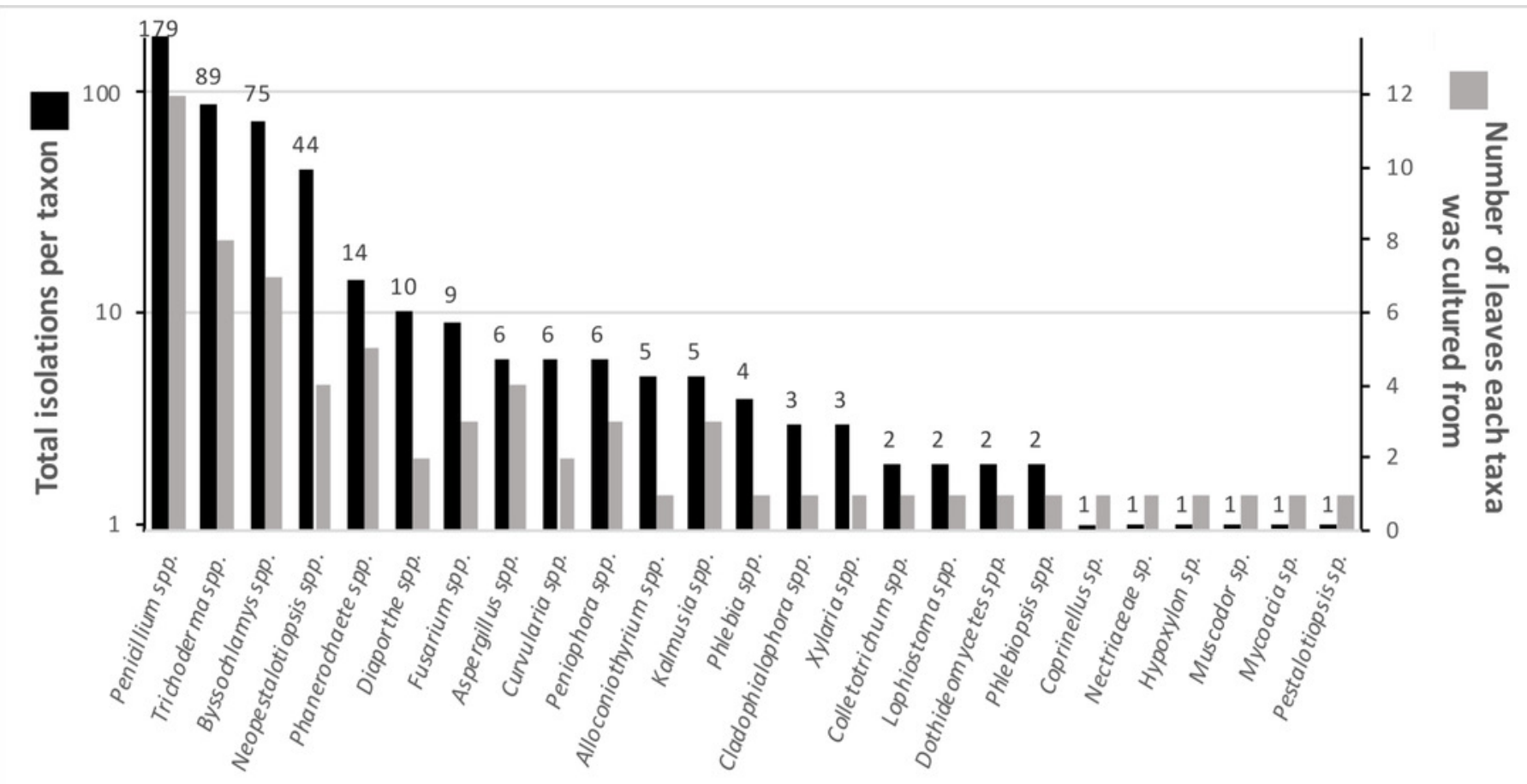


Figure 2

Species accumulation curve for viaphytes.

The culturing did not achieve a saturation of culturable viaphytic taxa.

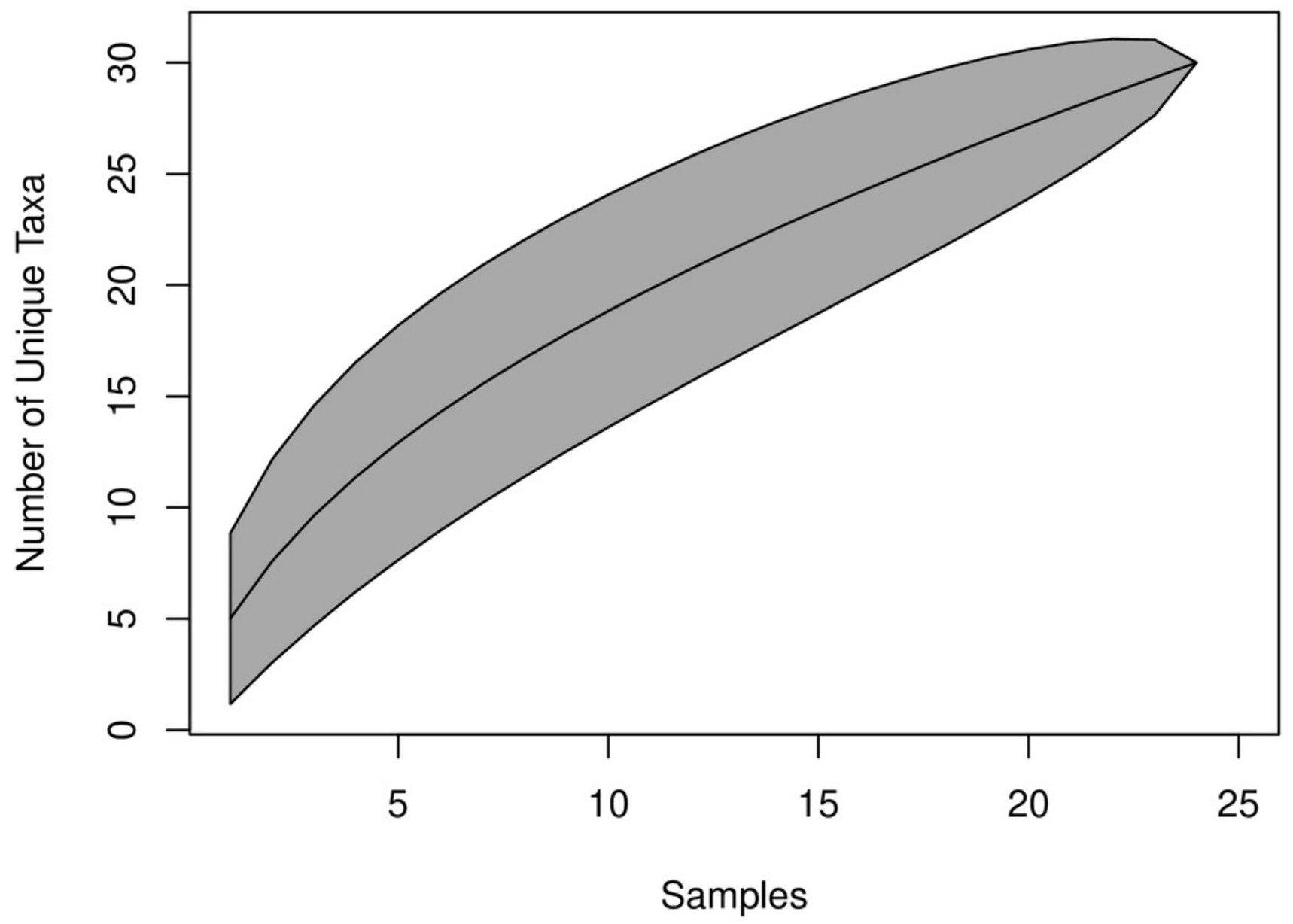


Figure 3

Non-metric Multidimensional Scaling (NMDS) plot of viaphyte communities.

Each point represents an individual birch tongue depressor; lines connect sticks that were inoculated with the same leaf; color indicates inoculation box.

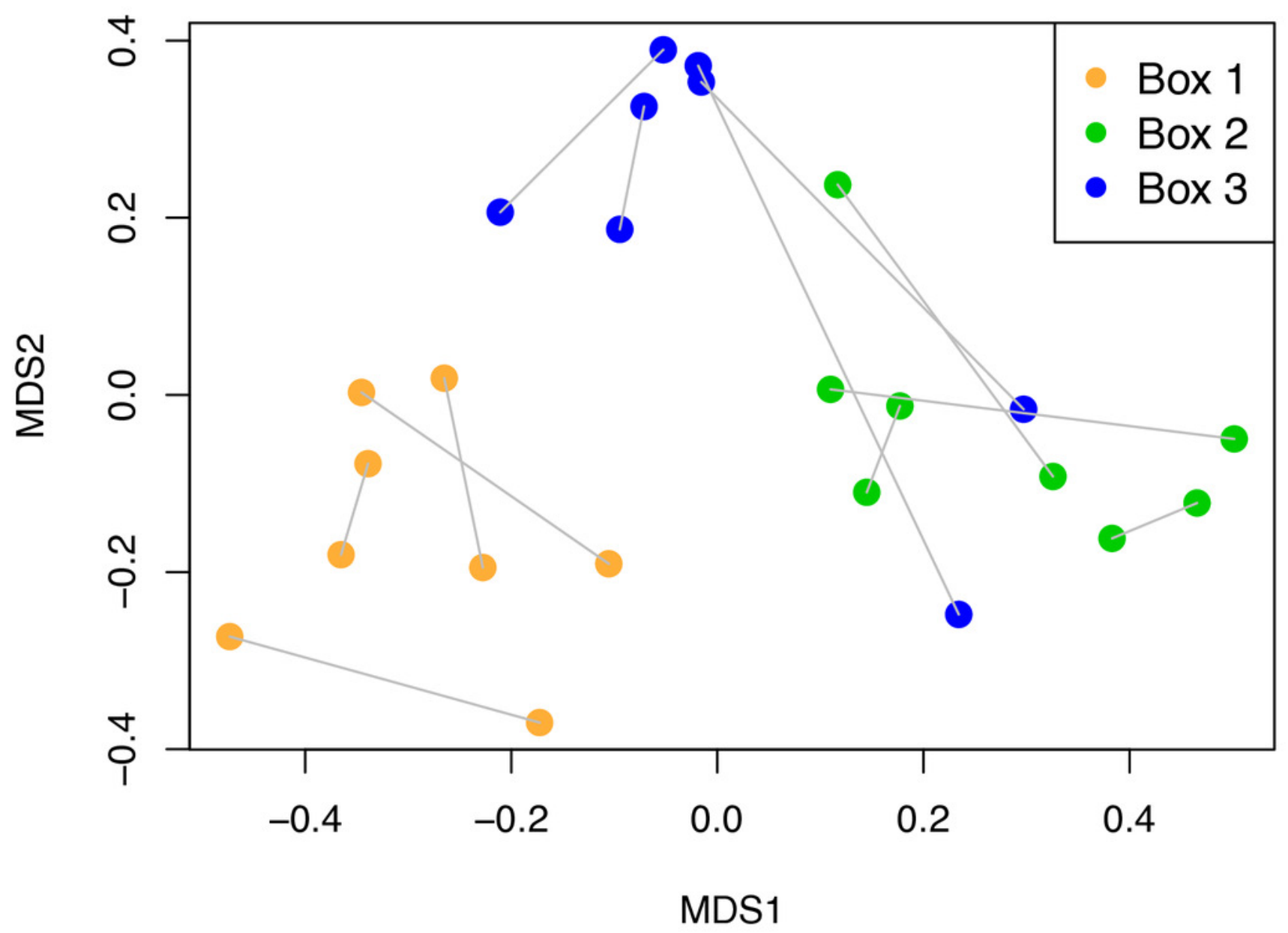

